\title{
A cross sectional evaluation of a total smoking ban at a large Australian university
}

\author{
Sharyn Burns*, Ellen Hart, Jonine Jancey, Jonathan Hallett, Gemma Crawford and Linda Portsmouth
}

\begin{abstract}
Background: Total smoking bans have been found to contribute positively to the health of non-smokers by reducing exposure to second-hand smoke, and to enhance the likelihood of cessation among smokers.

Methods: Two cross-sectional electronic surveys of staff and students at a large Australian university were conducted prior $(n=969)$ and 1 year post $(n=670)$ the implementation of a smoke free campus policy. Demographics, tobacco use, intention to quit, attitudes towards smoking and smoking restrictions and awareness of and attitudes towards the campus smoking policy were measured.

Results: Exposure to second-hand smoke $(\mathrm{SHS})$ reduced significantly $(\mathrm{p}<0.001)$ one year after policy implementation. Smoking prevalence was similar at both time periods (T1 9.3\%; T2 8.4 \%) and over half of smokers indicated they were planning to quit smoking in the future (T1 65.5 vs T2 $62.3 \%$ ). There was a significant increase in positive responses to the statement the campus should be totally smoke free including all outdoor areas at T2 compared to T1 (T1 60.8 vs T2 71.4\%; $p<0.001$ ), however respondents felt there should be places on campus for smokers to smoke (T1 53.6 vs T2 $47 \% ; p<0.05$ ).

Conclusions: This study found a significant positive difference in exposure SHS after implementation of the total ban. Although prevalence of smoking in this study was low, the proportion of respondents who were contemplating smoking cessation suggests support for smokers would be beneficial. Continued awareness raising, education and enforcement is likely to enhance the long term outcomes of the total ban.
\end{abstract}

\section{Background}

Australia has employed a coordinated, comprehensive approach to tobacco control since the 1980s [1,2] and as a result has experienced a significant decline in the social acceptability of tobacco use and smoking prevalence [3]. Despite substantial progress in reducing smoking prevalence and exposure to second-hand smoke (SHS), tobacco smoking remains the largest contributor to and one of the most preventable causes of ill-health in Australia [4].

One strategy employed as part of a comprehensive approach has been the introduction of smoke-free policies (prohibiting smoking in specific areas), which have been found to contribute to reductions in smoking rates

\footnotetext{
*Correspondence: s.burns@curtin.edu.au

Collaboration for Evidence, Research and Impact in Public Health, School of Public Health, Curtin University, GPO Box U1987, Perth, WA 6845, Australia
}

and in turn SHS exposure and improved health outcomes $[5,6]$. Australia has a long history of smoke-free policy with restrictions commencing in the 1970s [7] and by 2002 most enclosed public spaces were smoke-free in almost all Australian states and territories [7]. By 2010, smoking was banned in all non-hospitality workplaces, restaurants and bars in all jurisdictions in Australia [5]. Some high income countries, including Australia have extended smoke-free policies to outdoor spaces [5] consistent with Western Australian legislation smoking at this university was prohibited in all enclosed areas and cafes [8], however in 2012 the ban was extended to include all outdoor areas and university vehicles. Although US studies have demonstrated favourable changes in smoking behaviour [9] and exposure to SHS [10] as a result of a total smoke free policy implementation, there is a paucity of data describing the evaluation of total smoking bans in universities in Australia. 
Most Australians are aware of the harms of smoking and SHS; reflected by negative normative attitudes towards smoking [3]. These changes in attitudes over the last few decades have coincided with the implementation of smoke-free policies and declining prevalence of smoking rates [3, 7]. Smoke-free policies have been associated with reduced respiratory symptoms, improved lung function, and improved cardiovascular health for people who would have previously been exposed to SHS [11]. A study of the impact of tobacco bans in 15 Ontario municipalities found exposure to SHS decreased by $4.7 \%$ and $2.3 \%$ in public places and workplaces respectively over a 2 year period. The same study suggested these bans also reduced exposure to SHS in private settings including homes and cars [12].

While smoke-free policies assist in improving the health of non-smokers they also appear to impact on the health of smokers by reducing the amount of cigarettes smoked per day and to support motivation for cessation [5]. A US study found smoke-free laws (which included bans in at least one location including workplaces, restaurants and bars) were associated with decreased current and established smoking, but not with past year initiation among young adults [13]. Others have found total smoking bans to be more likely to promote quit attempts compared to partial smoking bans [14]. A study in California found smokers living in a city with a smoking ban in outdoor spaces were more likely to reduce smoking levels and to attempt to quit compared to those living in other cities [15]. A qualitative study of smokers at this university found some smokers felt the implementation of the total ban would provide good motivation for them personally to quit [16].

Policy support is a key factor for successful implementation; Australians, including smokers, are generally supportive of smoke-free policy $[5,17,18]$. Arguments used by opponents of smoke-free areas (e.g. the difficulty of enforcement and the risk that policies may be economically detrimental to specific industries, particularly the hospitality industry) have been unfounded [5]. Although only short term compliance has been measured, policy compliance is generally high in most countries, and studies assessing the impact of smoke-free policy implementation have found no changes to hospitality revenue [5]. Despite strong support for such policy in enclosed areas, extensions to include outdoor spaces may be met with greater resistance [5]. Support for smoking bans at a range of community venues including zoos, parks and community events has been found to be strongest for smaller outdoor venues. Women with children were more supportive of total bans than other respondents [19]. While overall support for total smoking bans in universities has been positive, both smokers and non-smokers have recognised the rights of smokers and suggested campuses provide designated places for smokers to smoke $[10,20]$.

A total smoking ban (including all buildings, grounds, outdoor areas, student housing and university vehicles) was implemented in a large university campus in Western Australia. Prior to this ban, smoking was prohibited in all buildings and undercover areas of the university. The university presents particular challenges for the implementation of a total ban due to the physical size of the ground (119 hectares, which includes student housing in addition to extensive outdoor areas including gardens, sports fields and natural bushland). In 2012 more than 35,000 students were located at the Bentley campus. Of the total student population approximately $80 \%$ were undergraduate students and $55 \%$ were female. Across all campuses the university employed 1378 academic and 1709 general staff (not including causal staff) of whom $54 \%$ were female. This paper reports on exposure to SHS, attitudes towards smoking, and awareness of and attitudes towards the policy according to smoking status at baseline and one year following implementation.

\section{Methods}

Two cross-sectional electronic surveys of staff and students were conducted, prior to the smoke free campus policy implementation (T1) and 1 year post policy implementation (T2). For each survey a random sample of students $(n=4500)$ and staff $(n=500)$ were invited to participate via email. Participants at T1 and T2 were matched to ensure samples were independent. Three participants who completed the survey on both occasions were excluded from the T2 analysis.

The use of a cross-sectional sample is often used in the exploration of attitudes towards and health behaviour compliance and policy implementation [21-24]. Surveys were sent from the University Surveys Office to participants meeting the inclusion criteria: aged over 18 years; staff working at the main campus or students enrolled internally and attending the main campus. Students were sent two and staff one follow-up reminder email. Reminder emails were kept to a minimum to reduce burden on staff and students and were limited due to project resources.

\section{Instrumentation}

The survey instrument collected data on demographics, tobacco use, attitudes towards smoking and smoking restrictions, awareness of and attitudes towards campus smoking policy and intentions to quit. All questions were developed based on previously validated instruments [17]. To ensure the survey was appropriate for the target audience it was tested for reliability using a test-retest 
$(\mathrm{n}=32)$, and for content validity using an expert panel of health promotion, research, and tobacco control professionals $(\mathrm{n}=8)$. Items with low internal consistency were removed or modified [17].

\section{Demographics}

Demographics included gender and primary role at the university. Primary role asked respondents to identify their main role at the university from four options: undergraduate student, postgraduate student, academic staff or general/professional (administrative/technical) staff [17].

\section{Tobacco use and second-hand smoke exposure}

Similar to other university-based studies $[25,26]$ four categories of smoking status were defined: non-smoker (never smoked cigarettes or never smoked regularly); exsmoker (previously smoked regularly-at least one cigarette a day); regular smoker (at least one cigarette a day); or occasional smoker (less than one cigarette a day on average). For the purpose of comparison with key independent variables the regular and occasional smoker variables were collapsed to form one variable (smoker). SHS exposure was measured by self-reported exposure to cigarette smoke on campus in the previous four weeks $[17,25,27]$.

\section{Attitudes towards smoking and smoking restrictions}

Questions on attitudes towards smoking were adapted from previously validated questions [27]. Attitudes towards a smoke-free campus were measured using questions adapted from a study of staff at Australian TAFEs (technical and further education-tertiary institutions offering a variety of vocational education and training) [28]. Response options included agree, neutral, and disagree [17].

\section{Awareness and attitudes towards campus smoking policy} Respondents were asked if they were aware of a campus smoking policy that restricted smoking on campus (response options: yes, no, don't know/not sure) and subsequently how they would describe the current campus smoking policy. Attitudes towards the impact of a smokefree campus were measured by four items: staff quality of life; student quality of life; student learning; and student enrolment with three responses: negative, neither negative nor positive, and positive.

\section{Data analysis}

Data was analysed using SPSS for Windows version 20.0. The dependent variable was tobacco use; independent variables included exposure to SHS, attitudes towards smoking, attitudes towards smoking bans, and awareness of campus smoking policy. Demographics of the sample were explored through descriptive statistics. Chi square analysis was used to explore the impact of a smoke-free campus for smokers, ex-smokers, and non-smokers. Due to the cross sectional nature of the study z-tests were calculated to explore any differences between the baseline and post samples [9]. Differences were considered significant at $\mathrm{p}<0.001$ and moderately significant at $\mathrm{p}<0.05$.

\section{Results}

Of the staff and students who were invited to participate, 969 respondents $(62.6 \%$ female) provided complete data at T1 and 670 (64.6\% female) at T2. This represented a response rate of $19.4 \%$ at $\mathrm{T} 1$ and $13.4 \%$ at $\mathrm{T} 2$.

There was no significant difference between gender, length of smoking or plans to quit smoking at T1 and T2. Use of tobacco was similar although there was a moderately significant difference in respondents who had previously smoked with T2 respondents being more likely to categorise themselves as an ex-smoker (T1 11 vs T2 $14.7 \%$; p < 0.05) (see Table 1). Smoking prevalence was similar at both time periods with 9.3 and $8.4 \%$ of respondents reporting to smoke at $\mathrm{T} 1$ and $\mathrm{T} 2$ respectively. Over half of smokers indicated they were planning to quit smoking in the future (T1 $65.5 \mathrm{vs} \mathrm{T2} 62.3 \%$ ). There was a significant difference in primary role at the University with more undergraduate students responding at baseline (61.8\%) compared to T2 $(54.3 \%)$ and a greater proportion of general/professional staff responding at T2 compared to T1 (T1 13.6 vs T2 $17.6 \%$ ). Demographics of respondents are described in Table 1.

\section{Second-hand smoke exposure}

Although respondents reported some exposure to SHS at both T1 (79.4 \%) and T2 (58.1\%), levels of exposure fell significantly between the two time periods $(\mathrm{p}<0.001)$. Approximately one-third of respondents (33.2 \%) reported no exposure to SHS while on campus during the past four week period at T2 compared to $15.2 \%$ at T1 ( $<<0.001$ ). At T1 $23.8 \%$ of respondents reported to have been exposed to SHS once or more daily and $34.8 \%$ at least once a week compared to 8.6 and $21.4 \%$ respectively at T2 $(\mathrm{p}<0.001)$ (Table 2$)$. At both time periods most respondents agreed that second-hand smoke causes harm (T1 84.1 vs T2 $85.1 \%$ ) however smokers were less likely to agree with this statement compared to the total population (T1 46.7 vs T2 $42.6 \%$ ).

\section{Attitudes towards smoking}

When all responses were considered, attitudes towards smoking were generally negative with little change in attitudes between T1 and T2 (see Table 2). Most respondents agreed that they would prefer to socialise in a smoke-free 
Table 1 Demographics and smoking status at T1 and T2

\begin{tabular}{|c|c|c|c|}
\hline & T1 & $\mathrm{T} 2$ & Significance $(p) T 1 / T 2$ \\
\hline \multicolumn{4}{|l|}{ Gender } \\
\hline Male & $362(37.4)$ & $237(35.4)$ & 0.412 \\
\hline Female & $607(62.6)$ & $433(64.6)$ & 0.412 \\
\hline Total & 969 & 670 & \\
\hline \multicolumn{4}{|l|}{ Primary role } \\
\hline Undergraduate student & $599(61.8)$ & $364(54.3)$ & $0.002^{* *}$ \\
\hline Postgraduate student & $141(14.6)$ & $108(16.1)$ & 0.384 \\
\hline General/Professional staff member & $132(13.6)$ & $118(17.6)$ & $0.027^{*}$ \\
\hline Academic staff member & $97(10)$ & $80(11.9)$ & 0.215 \\
\hline Total & 969 & 670 & \\
\hline \multicolumn{4}{|l|}{ Use of tobacco } \\
\hline Never smoked cigarettes at all, or never smoked them regularly (non-smoker) & $771(79.6)$ & $508(76.2)$ & 0.101 \\
\hline Do not smoke now but used to smoke them regularly (once or more per day) (ex-smoker) & $107(11)$ & $98(14.7)$ & $0.029^{*}$ \\
\hline Occasionally smoke (on average, less than one per day) (smoker) & $39(4)$ & $34(5.1)$ & 0.303 \\
\hline Currently smoke cigarettes (more than one per day) (smoker) & $51(5.3)$ & $22(3.3)$ & 0.059 \\
\hline Prefer not to answer & $1(0.1)$ & $5(0.7)$ & $0.033^{*}$ \\
\hline Total & 969 & 667 & \\
\hline \multicolumn{4}{|l|}{ Are you planning on quitting smoking? } \\
\hline Yes & $59(65.5)$ & 38 (62.3) & 0.682 \\
\hline No & $31(34.5)$ & $23(37.7)$ & $0.001^{*}$ \\
\hline Total & 90 & 61 & \\
\hline
\end{tabular}

${ }^{*} p<0.05,{ }^{* *} p<0.01$

environment (T1 83.8 vs T2 $85.1 \%$ ) and they would prefer to date a non-smoker (T1 84.8 vs T2 $86.5 \%$ ). A greater proportion of respondents suggested they would seek out smoke-free environments at T2 compared to T1 (T1 67.4 vs T2 $72.2 \%$; $<0.05$ ). For both time periods smokers reported more positive attitudes towards smoking compared to non-smokers and ex-smokers. Ex-smokers were significantly more likely to agree that second-hand smoke causes harm (T1: 80.4 vs T2: $82.8 \%$; < 0.05) and to agree that they would ask others around them not to smoke at T2 compared to T1 (T1 26.2 vs T2 $41.9 \%$; $\mathrm{p}<0.002)$.

\section{Attitudes towards smoke-free campus}

There was strong agreement that the campus should be smoke-free in all buildings at both time periods (T1 91.3 vs T2 $92.8 \%$ ). Although there was less agreement that the campus should be totally smoke-free including all outdoor areas there was a significant increase in positive responses to this statement at T2 compared to T1 (T1 60.8 vs T2 71.4\%; p < 0.001). This was true for non-smokers $(\mathrm{p}=0.017)$ and ex-smokers $(\mathrm{p}=0.014)$ however there was no statistical significance in responses for smokers between the two time periods ( $p=0.562$ ) (see Table 3). Respondents were significantly more likely to agree that restrictions on where you can smoke make it hard for smokers on campus at T2 compared to T1 (T1 38.5 vs T2 $56.6 \%$; p $<0.01$ ). Agreement with the statement at T2 was more likely for both non-smokers $(\mathrm{p}<0.001)$ and smokers $(\mathrm{p}<0.05)$. Non-smokers were less likely to agree that there should be some places on campus where people can go to smoke at T2 compared to T1 (T1 48.9 vs T2 $42.3 \%$; < 0.05), however there were no significant differences in attitudes towards this statement for ex-smokers or smokers between the two time periods.

\section{Awareness of campus smoking policy}

Awareness of campus smoke free policy increased significantly between $\mathrm{T} 1$ and $\mathrm{T} 2$ with $56 \%$ of respondents reporting they were aware that there was a smoke free policy at T1 compared to $79.8 \%$ at T2 (p < 0.001). However when this response was analysed by smoking status; awareness of the policy increased for non-smokers, ex-smokers and smokers, although changes were only significant for non-smokers and ex-smokers ( $\mathrm{p}<0.001)$. Awareness of specific aspects of the policy varied. At T1 $58.7 \%$ of respondents correctly identified that staff, students and visitors were allowed to smoke in designated areas of the campus but not inside the buildings. At T2, $65.9 \%$ of respondents correctly identified that smoking was now banned throughout the campus (Table 4). 
Table 2 Agreement with tobacco smoking attitude statements reported by University staff and students at T1 and T2

\begin{tabular}{|c|c|c|c|c|}
\hline $\begin{array}{l}\text { Total sample } \\
\text { Baseline }(n=968) \\
\text { Post }(n=636)\end{array}$ & Non-smokers $\mathrm{N}(\%)$ & Ex-smokers N (\%) & Smokers N (\%) & $\begin{array}{l}\text { Total \# of participants } \\
\text { who agree } N(\%)\end{array}$ \\
\hline \multicolumn{5}{|l|}{ Total } \\
\hline Baseline (T1) & 771 & 107 & 90 & \\
\hline Post (T2) & 489 & 93 & 54 & \\
\hline \multicolumn{5}{|c|}{ If someone smokes cigarettes around me they are causing me harm because of second-hand smoke } \\
\hline Baseline & $686(89)$ & $86(80.4)$ & $42(46.7)$ & $814(84.1)$ \\
\hline Post & $441(90.2)$ & $77(82.8)$ & $23(42.6)$ & $541(85.1)$ \\
\hline Significance (T1/T2) & 0.497 & 0.66 & 0.631 & 0.596 \\
\hline \multicolumn{5}{|c|}{ I prefer to socialise in a smoke-free environment } \\
\hline Baseline & $695(90.1)$ & $86(80.4)$ & $30(33.3)$ & $811(83.8)$ \\
\hline Post & $445(91)$ & $75(80.6)$ & $21(38.9)$ & $541(85.1)$ \\
\hline Significance (T1/T2) & 0.610 & 0.960 & 0.502 & 0.490 \\
\hline \multicolumn{5}{|c|}{ I seek out smoke-free environments } \\
\hline Baseline & $572(74.2)$ & $67(62.6)$ & $13(14.4)$ & $652(67.4)$ \\
\hline Post & $388(79.3)$ & $60(64.5)$ & $11(20.4)$ & $459(72.2)$ \\
\hline Significance (T1/T2) & $0.037^{*}$ & 0.779 & 0.358 & $0.041^{*}$ \\
\hline \multicolumn{5}{|c|}{ It disappoints me when a friend who normally doesn't smoke, smokes cigarettes while drinking } \\
\hline Baseline & $547(70.9)$ & $46(43)$ & $13(14.4)$ & $606(62.6)$ \\
\hline Post & $364(74.4)$ & $40(43)$ & $9(16.7)$ & $413(64.9)$ \\
\hline Significance $(\mathrm{T} 1 / \mathrm{T} 2)$ & 0.177 & 1 & 0.719 & 0.342 \\
\hline \multicolumn{5}{|c|}{ I would rather date a non-smoker } \\
\hline Baseline & $701(90.9)$ & $84(78.5)$ & $36(40)$ & $821(84.8)$ \\
\hline Post & $458(93.7)$ & $74(79.6)$ & $18(33.3)$ & $550(86.5)$ \\
\hline Significance $(\mathrm{T} 1 / \mathrm{T} 2)$ & 0.080 & 0.857 & 0.424 & 0.352 \\
\hline \multicolumn{5}{|c|}{ I ask others not to smoke around me } \\
\hline Baseline & $354(44.7)$ & $28(26.2)$ & $2(2.2)$ & $375(38.7)$ \\
\hline Post & $231(47.2)$ & $39(41.9)$ & $6(11.1)$ & $276(43.4)$ \\
\hline $\begin{array}{l}\text { Significance } \\
(\mathrm{T} 1 / \mathrm{T} 2)\end{array}$ & 0.646 & $0.018^{*}$ & $0.024^{*}$ & 0.062 \\
\hline
\end{tabular}

\section{Discussion}

\section{Second-hand smoke exposure}

This study found significant reductions in all levels of exposure to SHS over the two time periods. Despite these promising results only one-third of respondents (33.2\%) reported to have never been exposed to cigarette smoke at T2 which indicates SHS exposure remains present and unacceptably high. Smoke-free policies may drive smokers to the periphery of campus and thereby still expose students and staff to SHS during entry and exit to campus [10]. This is especially pertinent to this university as the grounds are large (116 hectares) with poorly lit perimeters making policy enforcement challenging [17].

The finding that a proportion of people continue to smoke on campus despite the ban is supported by an observational study at this university which was implemented to measure compliance. Of the 50 smokers observed, 37 agreed to participate in an intercept survey. Reasons for noncompliance with the policy included defiance, necessity to smoke, inconvenience of travelling off campus, unintentional noncompliance, and ease of avoidance of detection, which may stem from inadequate enforcement [29]. Enforcement is a key component to supporting smoke-free policy and it is recommended that it is implemented with initial warnings and education, progressing to penalties if individuals continue not to comply with the policy $[30,31]$.

\section{Prevalence of tobacco smoking}

Prevalence of tobacco smoking in this study was lower than for the general adult population in Australia (daily smoking $12.8 \%$ in 2013) [32] however these findings are consistent with other studies conducted at this university [25]. The implementation of the smoke-free policy 
Table 3 Agreement with tobacco control attitude statements reported by University staff and students at T1 and T2

\begin{tabular}{|c|c|c|c|c|}
\hline $\begin{array}{l}\text { Total sample } \\
\text { Baseline }(n=968) \\
\text { Post }(n=636)\end{array}$ & Non-smokers N (\%) & Ex-smokers N (\%) & Smokers N (\%) & $\begin{array}{l}\text { Total \# of participants } \\
\text { who agree } N(\%)\end{array}$ \\
\hline \multicolumn{5}{|l|}{ Total } \\
\hline Baseline (T1) & 771 & 107 & 90 & \\
\hline Post (T2) & 489 & 93 & 54 & \\
\hline \multicolumn{5}{|c|}{ Our campus should be smoke-free including all out door areas } \\
\hline Baseline & $517(67.1)$ & $54(50.5)$ & $18(20)$ & $589(60.8)$ \\
\hline Post & $378(77.3)$ & $63(67.7)$ & $13(24.1)$ & $454(71.4)$ \\
\hline Significance $(\mathrm{T} 1 / \mathrm{T} 2)$ & $0.000^{* *}$ & $0.014^{*}$ & 0.562 & $0.000^{* *}$ \\
\hline \multicolumn{5}{|c|}{ The restrictions on where you can smoke makes it hard for smokers on campus } \\
\hline Baseline & $275(35.7)$ & $54(50.5)$ & $44(48.9)$ & $373(38.5)$ \\
\hline Post & $262(53.6)$ & $58(62.4)$ & $40(74.1)$ & $360(56.6)$ \\
\hline Significance & $0.000^{* *}$ & 0.091 & $0.003^{* *}$ & $0.000^{* *}$ \\
\hline \multicolumn{5}{|c|}{ There should be some places on campus where people can go to smoke } \\
\hline Baseline & $377(48.9)$ & $72(67.3)$ & $70(77.8)$ & $519(53.6)$ \\
\hline Post & $207(42.3)$ & $54(58.1)$ & $38(70.4)$ & $299(47)$ \\
\hline Significance $(T 1 / T 2)$ & $0.023^{*}$ & 0.177 & 0.322 & $0.009^{* *}$ \\
\hline \multicolumn{5}{|c|}{ There should be more help or support at university for people who want to quit smoking } \\
\hline Baseline & $470(61)$ & $59(55.1)$ & $43(47.8)$ & $572(59.1)$ \\
\hline Post & $295(60.3)$ & $40(43)$ & $18(33.3)$ & $353(55.5)$ \\
\hline Significance $(\mathrm{T} 1 / \mathrm{T} 2)$ & 0.826 & 0.087 & 0.891 & 0.156 \\
\hline \multicolumn{5}{|c|}{ Because of their professional role, university staff have a responsibility to be non-smokers } \\
\hline Baseline & $280(36.3)$ & $20(18.7)$ & $8(8.9)$ & $308(31.8)$ \\
\hline Post & $191(39.1)$ & $22(23.7)$ & $8(14.8)$ & $221(34.7)$ \\
\hline Significance $(T 1 / T 2)$ & 0.327 & 0.39 & 0.271 & 0.223 \\
\hline \multicolumn{5}{|c|}{ Our campus should be smoke free in all buildings } \\
\hline Baseline & $724(93.9)$ & $97(90.7)$ & $63(70)$ & $884(91.3)$ \\
\hline Post & $467(95.5)$ & $88(94.6)$ & $35(64.8)$ & $590(92.8)$ \\
\hline Significance (T1/T2) & 0.226 & 0.289 & 0.516 & 0.298 \\
\hline \multicolumn{5}{|c|}{ Our campus should be completely smoke-free } \\
\hline Baseline & $553(71.7)$ & $63(58.9)$ & $20(22.2)$ & $636(65.7)$ \\
\hline Post & $345(70.6)$ & $57(61.3)$ & $10(18.5)$ & $412(64.8)$ \\
\hline Significance (T1/T2) & 0.653 & 0.726 & 0.596 & 0.704 \\
\hline
\end{tabular}

${ }^{*} \mathrm{p}<0.05,{ }^{* *} \mathrm{p}<0.01$

had little impact on the prevalence of smoking over the two time periods however this may be due to the low baseline prevalence and the short time period that the policy had been in place. Although studies have demonstrated success in reducing prevalence through the implementation of policy [9] it is also acknowledged that policy is best combined with other strategies [1, 33]. Over $60 \%$ of smokers in this study indicated they were planning to quit smoking in the future. Consistent with the Transtheoretical Model which helps to explain different stages of change in the behaviour change process, smokers in the contemplation and preparation stages are ideal participants for quit smoking interventions [34].

\section{Attitudes to smoking}

Attitudes towards tobacco smoking remained similar over the two time periods. Consistent with Australian data the majority of non-smokers reported negative attitudes towards smoking [3]. The lack of change may reflect the social norms associated with smoking in Australia [35] and/or the predominately policy based nature of the intervention as the policy implementation included minimal awareness raising strategies and quit sessions for staff.

Support for policy implementation has been identified as critical to success [36]. Similar to this study, US college studies have reported students to be generally supportive of smoke-free policy, especially smoke-free buildings 
Table 4 Staff and students awareness of campus tobacco smoking policy at T1 and T2

\begin{tabular}{|c|c|c|c|c|}
\hline $\begin{array}{l}\text { Total Sample } \\
\text { Baseline }(n=968) \\
\text { Post }(n=636)\end{array}$ & Non-smokers N (\%) & Ex-smokers N (\%) & Smokers N (\%) & $\begin{array}{l}\text { Total \# of participants } \\
\text { who agree with the } \\
\text { statement } N(\%)\end{array}$ \\
\hline \multicolumn{5}{|l|}{ Total } \\
\hline $\mathrm{T} 1$ & 771 & 107 & 90 & \\
\hline $\mathrm{T} 2$ & 489 & 93 & 54 & \\
\hline \multicolumn{5}{|l|}{ Awareness of policy } \\
\hline \multicolumn{5}{|l|}{ Yes } \\
\hline Baseline & $405(52.5)$ & $72(67.3)$ & $65(72.2)$ & $542(56)$ \\
\hline Post & $396(78.7)$ & $83(86.5)$ & $43(78.2)$ & $522(79.8)$ \\
\hline Significance (T1/T2) & $0.000^{* *}$ & $0.000^{* *}$ & 0.322 & $0.000^{* *}$ \\
\hline \multicolumn{5}{|l|}{ No } \\
\hline Baseline & $189(24.5)$ & $12(11.2)$ & $19(21.1)$ & $220(22.7)$ \\
\hline Post & $47(9.3)$ & $12(12.5)$ & $4(7.3)$ & $63(9.6)$ \\
\hline Significance $(\mathrm{T} 1 / \mathrm{T} 2)$ & $0.000^{* *}$ & 0.711 & $0.03^{*}$ & $0.000^{* *}$ \\
\hline \multicolumn{5}{|l|}{ Don't know/not sure } \\
\hline Baseline & $177(23)$ & $23(21.5)$ & $6(6.7)$ & $206(21.3)$ \\
\hline Post & $60(11.9)$ & $1(1)$ & $8(14.5)$ & $69(10.6)$ \\
\hline Significance (T1/T2) & $0.000^{* *}$ & $0.000^{* *}$ & 0.11 & $0.000^{* *}$ \\
\hline \multicolumn{5}{|l|}{ Describe the policy } \\
\hline \multicolumn{5}{|c|}{ No policy on tobacco smoking in place } \\
\hline Baseline & $43(5.6)$ & $4(3.7)$ & $3(3.3)$ & $50(5.2)$ \\
\hline Post & $22(4.4)$ & $3(3.1)$ & $6(10.9)$ & $31(4.7)$ \\
\hline Significance (T1/T2) & 0.401 & 0.842 & 0.062 & 0.697 \\
\hline \multicolumn{5}{|c|}{ Staff, students, and visitors are allowed to smoke tobacco in designated areas of campus buildings } \\
\hline Baseline & $65(8.4)$ & $9(8.4)$ & $13(14.4)$ & $87(9)$ \\
\hline Post & $25(5)$ & $4(4.2)$ & $2(3.6)$ & $31(4.7)$ \\
\hline Significance (T1/T2) & $0.026^{*}$ & 0.238 & $0.041^{*}$ & $0.001^{* *}$ \\
\hline \multicolumn{5}{|c|}{ Staff, students, and visitors are allowed to smoke tobacco in designated areas of the campus grounds but not inside the buildings } \\
\hline Baseline & $447(58)$ & $65(60.7)$ & $56(62.2)$ & $568(58.7)$ \\
\hline Post & $62(12.3)$ & $10(10.4)$ & $4(7.3)$ & $76(11.6)$ \\
\hline Significance $(\mathrm{T} 1 / \mathrm{T} 2)$ & $0.000^{* *}$ & $0.000^{* *}$ & $0.000^{* *}$ & $0.000^{* *}$ \\
\hline \multicolumn{5}{|c|}{ Staff, students, and visitors are banned from smoking tobacco throughout the campus; this includes all university buildings grounds and vehicles } \\
\hline Baseline & $61(7.9)$ & $11(10.3)$ & $5(5.6)$ & $77(8)$ \\
\hline Post & $324(64.4)$ & $69(71.9)$ & $38(69.1)$ & $431(65.9)$ \\
\hline Significance (T1/T2) & $0.000^{* *}$ & $0.000^{* *}$ & $0.000^{* *}$ & $0.000^{* *}$ \\
\hline \multicolumn{5}{|l|}{ Don't know/not sure } \\
\hline Baseline & $155(20.1)$ & $18(16.8)$ & $13(14.4)$ & $186(19.2)$ \\
\hline Post & 70 (13.9) & $10(10.4)$ & $5(9.1)$ & $85(13)$ \\
\hline Significance (T1/T2) & $0.009^{* *}$ & 0.219 & 0.363 & $0.001^{* *}$ \\
\hline
\end{tabular}

${ }^{*} p<0.05,{ }^{* *} p<0.01$

$[20,37]$ and the reduction of SHS, however they were less likely to agree that the campus should be totally smokefree [20]. Although the current study found around half of all respondents felt there should be places people can go to smoke on campus at both time periods this was lower (T1 53.6 vs T2 $47 \%$; $<$ < 0.05) at T2. As in this study, a US study found while smokers were more likely to agree that there should be some places on campus to smoke, non-smokers also felt smokers had the right to smoke on campus [20]. While $92.8 \%$ of respondents in the current study felt the campus should be smoke-free in all buildings at T2 only $64.8 \%$ felt the campus should be completely smoke-free. There was no significant difference in these responses over the two time periods. Similarly, another US study reported that over $70 \%$ of college students and staff agreed that their campus 
should be totally smoke-free [10]. Consistent with other studies [10] the current study found smokers to be least supportive of smoke-free policy. Despite changing norms towards smoking, and support generally being shown for smoke-free policies by smokers, some studies still find this group to be unsupportive of smoke-free policies which may translate into non-compliance $[17,28]$.

While changes in policy awareness were positive between the two time periods, over one-third of respondents $(34.1 \%)$ were not aware of the specific restrictions associated with the total ban on smoking on campus at $\mathrm{T} 2$ supporting the need to continue to promote and enforce the policy. Successful implementation of smokefree policy should include a comprehensive range of strategies (for example, awareness raising, education, quit sessions) and the policy needs to be consistently enforced [5, 17]. Other studies assessing the implementation of smoke-free policy in large learning institutions have found that enforcement can be difficult even when there is a perception of high compliance among the population [28, 38]. Staff and students from a New Zealand university suggest compliance should be enforced, potentially by campus security [31]. Similarly, key stakeholders and staff and student smokers from this university suggested enforcement to be an important consideration for the effectiveness of the policy, however given the extensive grounds of this university this would be challenging unless sufficient resources were provided [16, 17]. Currently the policy is enforced by Campus Security staff who issue a warning or fine to repeat offenders.

A successful smoke-free policy can educate the community on the health benefits of not smoking, and provide assistance for smoking cessation [17, 22, 39] however policy implementation needs to also consider the stigmatisation of smokers and in the case of this campus, smokers safety if they are to leave grounds to smoke $[16,29]$. A qualitative study conducted at this university found smokers to feel stigmatised and marginalised [16]. While stigmatising smoking has been a strategy of smoking control programs [10] there has been less focus on the unintended consequences which may include guilt, poor self-esteem and continued maintenance of smoking [40]. It is recommended public health interventions consider the negative psychological consequences of stigmatization and include strategies that focus on positive reinforcement and cessation support [40].

Universities provide a challenging yet important setting for health promotion. For young university students time at university represents an important transitional period where health behaviours such as tobacco use may become established [25]. While universities provide a range of social experiences which have the potential to influence smoking initiation and maintenance [25, 41] they also provide an ideal setting to positively impact health behaviours, including tobacco use [25].

\section{Limitations}

The cross sectional nature of this study precludes any causal effects. The low proportion of smokers who participated in this survey, while similar to other Australian university and TAFE $[25,28]$ and New Zealand university [31] studies may be due to selective non-reporting or under-reporting [26]. The low response rate, while similar to other studies $[28,42]$ is a limitation, however this study had limited resources for incentives and follow up. Although there are slightly more female students (55\%) and staff (54\%) at the university the overrepresentation of females (64.6\%) is also a limitation of this study. A higher proportion of smokers may have resulted in more positive attitudes towards smoking and more negative views of related policy.

\section{Conclusions}

Despite minimal supporting strategies, the implementation of the total smoking ban on campus resulted in significant reductions in exposure to second-hand smoke on a daily and weekly basis. While smoking prevalence did not change during the one year time period this was low at T1 $(9.3 \%)$. The study found strong support for the policy, however as expected smokers were least likely to support the total ban. The findings demonstrate the benefits of total smoking bans in large institutions but also highlight the need for a range of coordinated strategies which include awareness raising, education and enforcement, with targeted intervention such as cessation support available for those who smoke.

\section{Abbreviations \\ SHS: second-hand smoke; T1: data collection: time period 1;T2: data collec- tion: time period 1. \\ Authors' contributions \\ $\mathrm{SB}, \mathrm{EH}, \mathrm{JJ}, \mathrm{JH}, \mathrm{GC}$ have made substantial contributions to the conception and design of the paper. SB and $\mathrm{EH}$ made substantial contributions to the data analysis. SB, JJ, JH, GC, LP were involved in planning and implementing the intervention. All authors reviewed the article for important intellectual content. All authors read and approved the final manuscript.}

\section{Acknowledgements}

We would like to acknowledge Nicole Bowser who was the project officer for this study. We would also like to acknowledge the participants of this study who gave their time to complete the survey, the Curtin Office for Strategy and Planning for help administering the survey.

\section{Competing interests \\ The authors declare that they have no completing interests.}

\section{Ethical approval}

Curtin University Human Research Ethics Committee provided approval for this study (SPH-28/2011).

\section{Informed consent}

Participants provided consent at the time of the online survey completion. 
Received: 24 April 2016 Accepted: 15 May 2016

Published online: 26 May 2016

\section{References}

1. Burns SK, Portsmouth L. Health promotion. In: Felicity A, editor. Health psychology and behaviour in Australia. Sydney: McGraw Hill; 2010. p. 457-86.

2. Swanson MG, Durston B. Tobacco control legislation and public policy in Western Australia, 1911-2007. In: Australia CCW, editor. The progress of tobacco control in Western Australia: achievements, challenges and hopes for the future. Perth: The Cancer Council of Western Australia; 2008. p. 77-88.

3. Chapman S, Freeman B. Markers of the denormalisation of smoking and the tobacco industry. Tob Control. 2008;17:25-31.

4. Australian Institute of Health and Welfare: 2010 National Drug Strategy Household Survey report. Drug statistics series no. 25. Cat. no. PHE 145. In: Canberra: Australian Institute of Health and Welfare; 2011.

5. Hyland A, Barnoya J, Corral JE. Smoke-free air policies: past, present and future. Tob Control. 2012;21:154-61.

6. International Agency for Research on Cancer WHO. Evaluating the Effectiveness of Smoke-free Policies, vol. 13. Lyon: IARC Handbooks of Cancer Precention, Tobacco Control; 2009.

7. White V, Hill D, Siahpush M, Bobevski I. How has the prevalence of cigarette smoking changed among Australian adults? Trends in smoking prevalence between 1980 and 2001. Tob Control. 2003;12(Supplement 2):ii67-74.

8. Health. Do: Tobacco Products Control Act. Smoking in enclosed public places. Perth: Department of Health Western Australia; 2006. p. 2006

9. Seo DC, Macy JT, Torabi MR, Middlestadt SE. The effect of a smoke-free campus policy on college students'smoking behaviors and attitudes. 2011. Prev Med. 2011;53(4-5):347-52.

10. Braverman MT, Hoogesteger LA, Johnson JA. Predictors of support among students, faculty and staff for a smoke-free university campus. Prev Med. 2015;71:114-20.

11. Goodman P, Haw S, Kabir Z, Clancy L. Are there health benefits associated with comprehensive smoke-free laws. Int J Pub Health. 2009:54:367-78.

12. Naiman $A B$, Glazier $\mathrm{RH}$, Moineddin $\mathrm{R}$. Is there an impact of public smoking bans on self-reported smoking status and exposure to secondhand smoke? BMC Pub Health. 2011;11:146.

13. Farrelly MC, Loomis BR, Kuiper N, Han B, Gfroerer J, Caraballo RS, Pechacek TF, Couzens L. Are tobacco control policies effective in reducing young adult smoking? J Adolesc Health. 2013;54:481-6.

14. Borland R, Yong HH, Siahpush M, Hyland A, Campbell S, Hastings G, Cummings KM, Fong GT. Support for and reported compliance with smokefree restaurants and bars by smokers in four countries: findings from the International Tobacco Control (ITC) four country survey. Tobacco Control. 2015:15:34-41.

15. Zablocki RW, Edland SD, Myers MG, Strong DR, Hofstetter R, Al-Delaimy WK. Smoking ban policies and their influence on smoking behaviors among current California smokers: a population-based study. Prev Med. 2014:59:73-8.

16. Burns S, Bowser N, Smith J, Jancey J, Crawford G. An exploratory study of smokers and stakeholders expectations of the implementation of a smoke free policy in a university setting. Health Promotion J Aust. 2014;25(2):129-35.

17. Burns S, Jancey J, Bowser N, Comfort J, Crawford G, Hallett J, Shields B, Portsmouth L. Moving forward: a cross sectional baseline study of staff and student attitudes towards a totally smoke free university campus. BMC Pub Health. 2013;13:738-43.

18. Hyland A, Higbee C, Borland R, Travers M, Hastings G, Fong GT, Cummings KM. Attitudes and beliefs about secondhand smoke and smoke-free policies in four countries: findings from the International Tobacco Control Four Country Survey. Nicotine Tob Res. 2009;11(6):642-9.

19. Rosenberg M, Pettigrew S, Wood L, Ferguson R, Houghton S. Public support for tobacco control policy extensions in Western Australia: a cross-sectional study B. BMJ Open. 2012;2:e000784

20. Loukas A, Garcia MR, Gottlieb NH. Texas college students' opinions of no-smoking policies, secondhand smoke, and smoking in public places. J Am Coll Health. 2006:55:27-32.
21. Fichtenberg CM, Glantz SA. Effect of smoke-free workplaces on smoking behaviour: systematic review. Br Med J. 2002;325(7357):188.

22. Martinez C, Fu M, Martinez-Sanchez J, Anton L, Fernandez P, Ballbe M, Andres A, Riccobene A, Sureda X, Gallart A, et al. Impact of a long-term tobacco-free policy at a comprehensive cancer center: a series of crosssectional surveys. BMC Pub Health. 2014;14(1):1228.

23. Mullooly JP, Schuman KL, Stevens VJ, Glasgow RE, Vogt TM. Smoking behavior and attitudes of employees of a large $\mathrm{HMO}$ before and after a work site ban on cigarette smoking. Pub Health Rep. 1990;105(6):623-8.

24. Rhodes RE, Plotnikoff RC. Can current physical activity act as a reasonable proxy measure of future physical activity? Evaluating cross-sectional and passive prospective designs with the use of social cognition models. Prev Med. 2005:40(5):547-55.

25. Howat P, Hallett J, Kypri K, Maycock B, Dhaliwal S, McManus A. Tobacco smoking in an Australian university sample and implications for health promotion. Prev Med. 2010;51:425-6.

26. Kypri K, Baxter J. Smoking in a NewZealand university sample. NZ Med J. 2004;117:1-6

27. Le L, Dhaliwal S, Howat P. University student attitudes to smoking policies. In Perth, Western Australia: Western Australian Centre for Health Promotion Research, the Centre for Behavioural Research in Cancer Control. Perth: Curtin University; 2008

28. Bonevski B, Paul CL, Walsh RA, Bryant J, Lecathelinais C. Support for smoke-free vocational education settings: An exploratory survey of staff behaviours, experiences and attitudes. Health Promotion J Aust. 2011;22:11-6.

29. Jancey J, Bowser N, Burns S, Crawford G, Portsmouth L, Smith J. No smoking here: examining reasons for noncompliance with a smoke-free policy in a large university. Nicotine Tob Res. 2014;16(7):976-83.

30. Fennell R. Should college campuses become tobacco free without an enforcement plan? J Am Coll Health. 2012:60(7):491.

31. Marsh L, Robertson LA, Cameron C. Attitudes towards smokefree campus policies in New Zealand. NZ Med J. 2014;127(1393):87-98.

32. Australian Institute of Health and Welfare. National drug strategy household survey detailed report 2013. Drug statistics series no. 28. Cat. no. PHE 183. In: Canberra: AlHW; 2014.

33. Murphy-Hoefer R, Griffith R, Pederson LL, Crossett L, Iyer SR, Hiller MD. A review of interventions to reduce tobacco use in colleges and universities. Am J Prev Med. 2005;28(2):188-200.

34. Prochaska JO, Velicer WF. The transtheoretical model of health behavior change. Am J Health Promotion. 1997;12(1):38-48.

35. Chapman S, Freeman B. Markers of the denormalisation of smoking and the tobacco industry. Tob Control. 2008;17:25-31.

36. Goodman RM, Steckler A, Kegler MC. Mobilizing organisations for health enhancement: theories of organisational change. In: Glanz K, Rimmer BK, Viswanath K, editors. Health behavior and health education. San Francisco: Jossey-Bass; 2002.

37. Rigotti NA, Regan S, Moran SE, Wechsler H. Students' opinion of tobacco control policies recommended for US colleges: a national survey. Tob Control. 2003;12(3):251-6

38. Watson D, Glover M, McCool J, Bullen C, Adams B, Min S. Impact of national smokefree environments laws on teachers, schools, and early childhood centres. Health Promotion J Aust. 2011:22:166-71.

39. Kouvonen A, Kivimaki M, Oksanen T, Pentti J, Heponiemi T, Vaananen A, Virtanen M, Vahtera J. Implementation of workplace-based smoking cessation support activities and smoking cessation among employees: the finnish public sector study. Am J Pub Health. 2012:102(7):e55-62.

40. Evans-Polce RJ, Castaldelli-Maia JM, Schomerus G, Evans-Lacko SE. The downside of tobacco control? Smoking and self-stigma: a systematic review. Soc Sci Med. 2015;145:26-34.

41. Burns S, Crawford G, Hallett J, Jancey J, Portsmouth L, Hunt K, Longo J. Consequences of low risk and hazardous alcohol consumption among university students in Australia and implications for health promotion interventions. Open J Preventive Med. 2015:5:1-13.

42. Hahn EJ, Fallin A, Darville A, Kercsmar SE, McCann M, Record RA. The three Ts of adopting tobacco-free policies on college campuses. Nurs Clin North Am. 2012;47(1):109-17. 